\title{
Examining the Movement Differences in the Behavior of Normal and Rack Railway Vehicle
}

\author{
A. NAGY1 I. LAKATOS ${ }^{2}$ \\ 1Széchenyi István University, GVIK,Department of Road\&Rail Vehicles, nagy.andor@sze.hu \\ ²zéchenyi István University, GVIK,Department of Road\&Rail Vehicles, lakatos@sze.hu
}

Abstract. The rack railway is a special type of railroad. There weren"t much built worldwide, and their number is decreasing. Now, in Budapest, there is a possibility to create an interoperable vehicle, based upon the experience gained from the previously operated line, and all the research regarding its unique characteristics. One from the many important sector of its operation, is the rail/rack/vehicle system. Its mechanical model is far more complex than a traditional railroad vehicle. We will demonstrate its behaviorial differences from a traditional railroad vehicle.

Keywords: rack railway, cogwheel railway, assimmetric rail bogie behavior, differences in axle box pressures

\section{Introduction}

In my recent activity, I had the luxury of dealing with a very unique problem, that has mostly no academic background that is accessible. This area of study is the rack railways, where the classic railway principles have pretty minor use. Usually, nowadays when I'm making a presentation, I start my speech with warning the audience, that they are supposed to forget mostly everything that they know about traditional railway systems. On the rack railway, we don't use the flanged rail wheel to transmit the force of traction or braking to the rail, but only keeping the vehicle on track. The traction and braking force is presented by a massive cogwheel per braked and/or traction and braking bogie, and some of the wheels are fixed on the axles, and some aren't. At the first sight, it seems like somebody just messed up a lot of complicated railway vehicle parts, and tried out whether they are capable of going on the rail, or not.

\section{The rack and the cogwheel}

\subsection{The systems, that are used around the world ${ }^{1}$}

\subsubsection{Blenkinsop}

This is the oldest system. It was created in the year of 1812, because John Blenkinsop thought, that his locomotive will not be able to haul all the loads, de to the limited friction between the rails, and its wheel flanges. So he created a three-wheeler monster, that had two normal flanged railway wheels, 
and one between them, same size, but a large cogwheel, that was connected to the rack, what was on the outer edge of one of the running rails at that time.

This system was used for 25 years, by the Middleton Rail. The most spectacular thing is, that the friction would be whole enough to haul all its load, because the track was laid on an almost flat surface, without high hills to climb. This method is not used anymore.

\subsubsection{Marsh system}

The Marsh system was created in 1861, by a magneficent engineer, Sylvester Marsh, who was working for Mount Washington Cog Railway. He made a patent out of his system. The pinions of the cogwheel were high, to prevent the climbing up of the bogey itself onto the rack. The Mount Washington RR was opened for public in 1868.

\subsubsection{Riggenbach system}

In 1871, Niklaus Riggenbach invented his own rack system. It is easy to notice, that the inventors of these rack railway systems were physically far away from each other, so mostly, the ideas were developing independent. He got a French patent for his work, on 1863. Despite their independent work with Marsh, Swiss officials and investors were so excited about Marsh's rack railway, that they have given a tremendous financial support to Riggenbach, and have given the full Swiss commission to him. So the Viznau-Rigi Bahn was opened in 1871. His system is more or less similar to Marsh's, but the cogwheel's pinions are not that deep, and he used U-profiles instead of Marsh's "L" profiles to hold the pins between them, functioning as a rack. This system is very expensive to build, as it is necessary to weld or cast the pins together with the side supports, practically functioning as a ladder. Based upon the success, Riggenbach founded IGB (Maschinenfabrik der Internationalen Gesellschaft für Bergbahnen) , a factory that has produced rack railway locomotives.

\subsubsection{Abt system}

This system was invented in 1882 by Carl Roman Abt, not suprisingly a swiss inventor, and locomotive engineer. He was working for Riggenbach previously. He designed a method to simplify the manufacturing of the rack itself, using multiple bars, that were machined, to create artificial teeth. Then two or three rods were mounted paralel to each other, but with an offset of the teeth. The cogwheel was produced according to this layout, so compared to the Riggenbach system, the rack could be lighter, easier to manufacture, and because of the rack teeth offset, the connection forces between the rack and the climbing cogwheel, were more constant. His first system was built in 1885, at the Harzbach Rail.

\subsubsection{Strub system}

Emil Strub, created the most popular rack rail system in 1896. There are very few changes to it, since then. This is also used by Budapest Rack Railway, and Strba, in Slovakia. The rack itself is machined into a flat foor rail, so this has became the cheapest rack railway. Usually when using this, the cogwheel is mounted between the flanged wheels, on the same axle as the wheelset's axle, but it has to move independent from the wheels. Strub had his patent on this system in 1896. 


\subsubsection{Locher system}

This system was designed by Eduard Locher. Its main difference from Strub, that the rack is not vertical, but horizontal, and the cogwheel's axle is placed 90 degrees towards the wheelset axle. Normally they use a two side machnined horizontal rack, where the rack's teeth are facing outwards from the center line of the track. Locher proved, that on a steeper grade than $25 \%$,the Abt system cogwheel climbs onto the top of the rack, and derails the car. So he started to design, and successfully built Pilatus bahn, that is the steepest cogwheel railroad on the world. Next to its superficial safety, the only disadvantage is that normal railroad-like switches are not applicable. Instead of these, a turntable is used.

\subsubsection{The Morgan and Lamella systems}

These last two, are not original inventions, howewer, they deserve to be mentioned. Morgan combined the vertical rack, with a collector rail, to be able to supply his electric locomotive with high voltage. It was deployed in the year of 1900 , in Chicago city. Its maximum steepness was $16 \%$. Lamella is practically a more developed Abt rack, planed to replace the Strub, due to the shortage of its raw material. Lots of the cogwheel railways are using a re-designed combination of Strub and Lamella.

\subsection{Rack railway bogies}

It can clearly be seen that all of the systems are limiting the movement of the axle, and indirectly the bogie and the vehicle on the track. I'm not working with Abt or Locher or any other systems then Strub. I have the possibility to access Budapest Cogwheel Railway, and conduct my measurements and experiments there, so mostly the achievements that may be read here, are from Strub system. Following the most recent derailments of Budapest Cogwheel Railway, I am the acting accident investigator in these cases, and from the science side, I want to dig myself deeper to the almost forgotten science of the rack railways. The aim is to proof all aspects from vehicle side and track side, that may cause the vehicle to derail.

It is important, to mention, that the generic rack rail vehicle can contain the following bogie types:

a) traction and brake bogie: the propulsion and deceleration equipment are built into this bogie, this is the most complex structure of the vehicle. One axle has the cogwheel mounted on, but the other is just an unbreakable, support axle.

b) brake bogie: there is no traction motor in this bogie, but through a cogwheel it can brake the vehicle, the other axle is just a support axle, with no propulsion or brake equipment.

c) support bogie: has no traction or braking equipment, just supports the weight of the vehicle

In my point of view, the support bogie has the least possibility to derail, as it has no connection with the rack, and the axle distance in it is smaller than the other bogies, which are in terms of dimensions identical.

The bogie itself is a complicated, and assimetric part. (It can be seen sideways in Fig.1.) If we measure the pivot pressures on the wheels, we will find that the differences between the wheels, can be 
sometimes bigger than $5 \%$ ! This is unacceptable by a traditional railroad vehicle, especially by high speed railways. (Over $120 \mathrm{~km} / \mathrm{h}, 2 \%$ is acceptable)

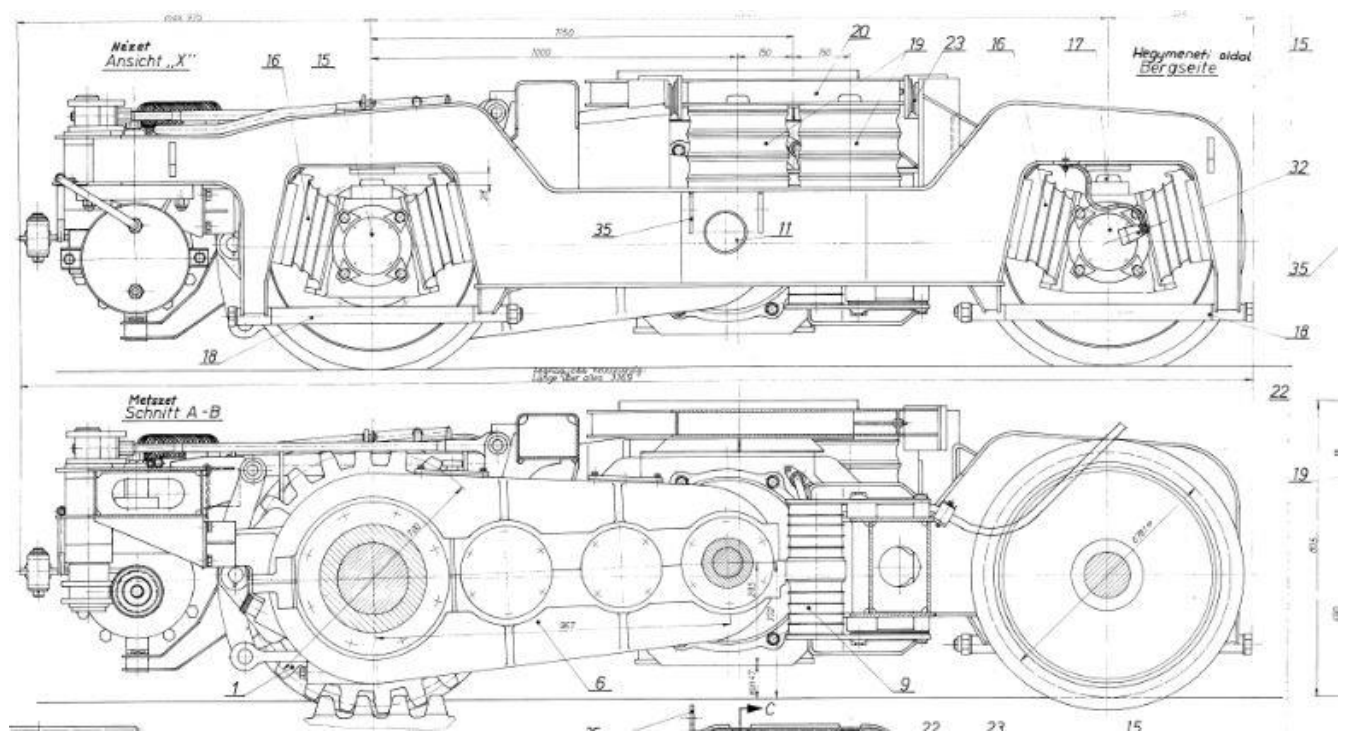

Figure 1: Traction bogie (Source: Simmering-Graz-Pauker)

When we look at this bogie, it is far away from conventional. The center of gravity is on a parallel, but different vertical line than the center plate. If we change the view to top view, we'll see the complicated layout of the bogie. (Fig.2.)

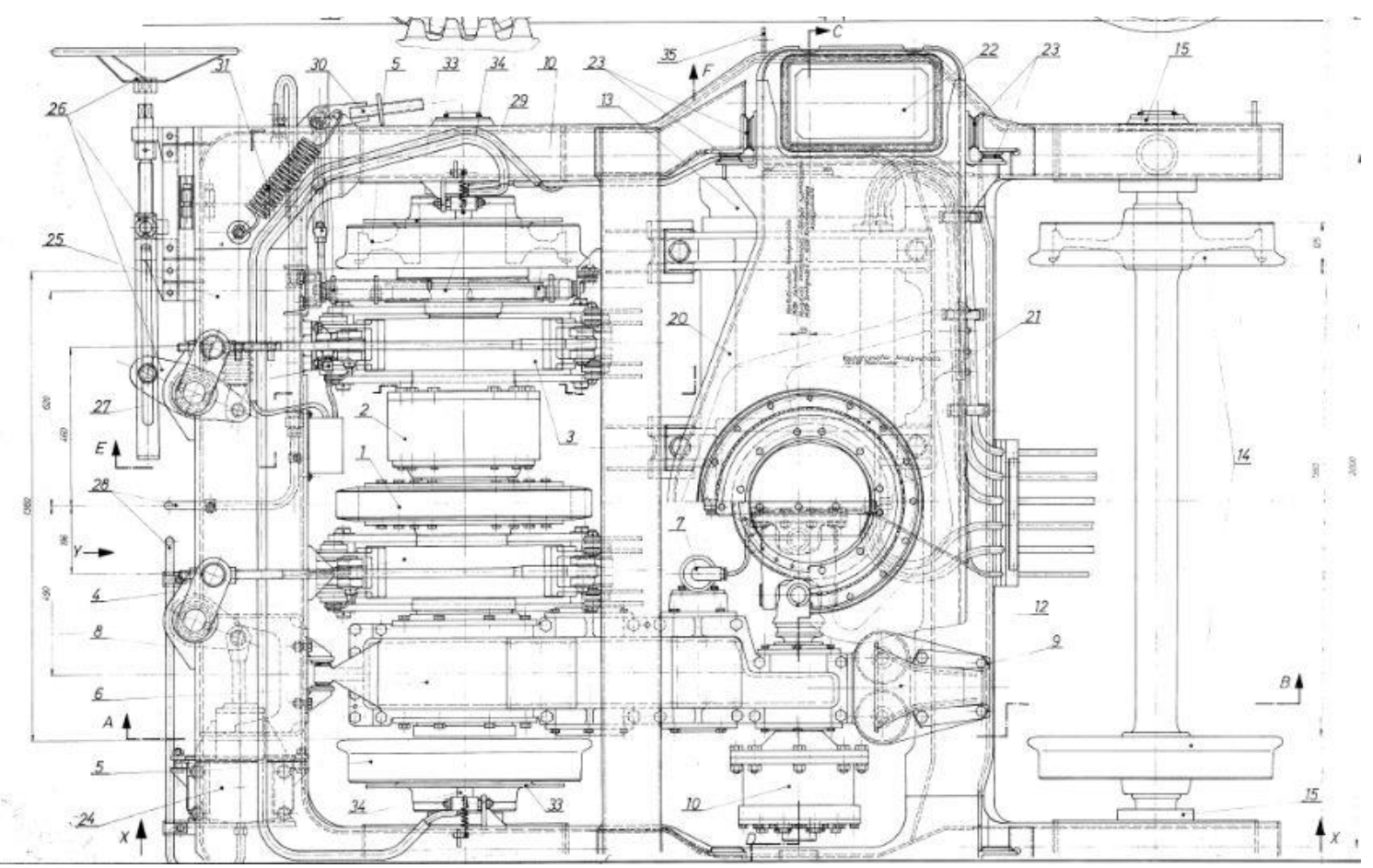

Figure 2: Traction bogie top view (Source: Simmering-Graz-Pauker) 


\subsection{Regulatory background}

There are a very few regulations that are affecting the track layout of the rack railway, in Hungary, there is a publication that describes the building and maintenance of tramways and rack railway, the rack railway related pages do not exceed 25 pages. The track has its unique characteristics too:

a) There is no transition curve by the curves, there is the straight part of the track, then - boom there is the curve. This limits the speed as well, as the side accelerations can be pretty big, and this single handedly can cause the train to derail. Due to the reduced speed of the operation ( $25 \mathrm{~km} / \mathrm{h}$ uphill, $20 \mathrm{~km} / \mathrm{h}$ downhill over $50 \%$ steepness, under $50 \%$ the maximum is $25 \mathrm{~km} / \mathrm{h}$ ) the designers sacrificed the transition curve, not to mention its extremity to be designed, caused by the limited flexibility of the rack itself.

b) Superelevation is applied in all the curves, but extreme care must be taken, because we need to adjust the level of the rack as well, and its angle compared to the vertical perpendicular must be also carefully adjusted, in other case, the cogwheel will climb out of the rack. If the curve's outer rail is lower than the superelevated rack's outer edge, the wheel stops being as a support to the vehicle, and the rack will carry the weight, that supposed to be carried by the specific wheel.

\section{Behavior of the bogie}

\subsection{Irregular movements of a rack railway vehicle}

\subsubsection{Iregular movements}

When tracing a normal bogie, we can experience the classic mechanical movement of a normal railroad bogie. Hypothetically, we assume that all the wheelsets are a part of a torsion system. But this is only true by the classic railroad bogie. (Fig.3.)

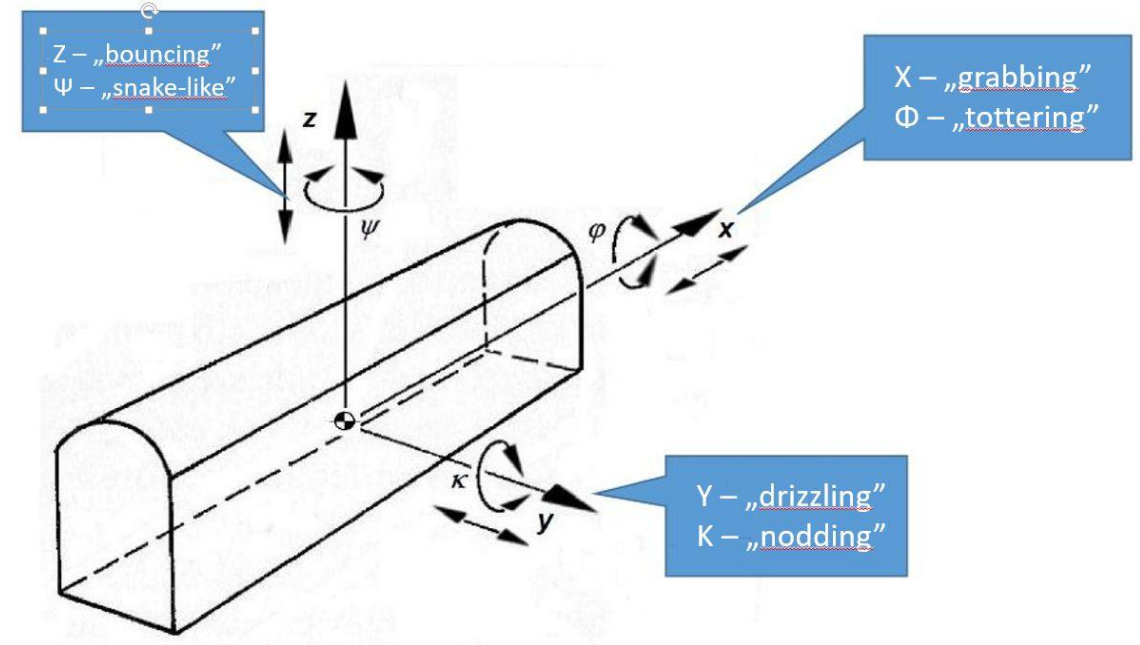

Figure 3: Irregular movements of a normal railroad car (Source: The authors own drawing) 
Because of its mechanical design, not all of the axles can behave itself like a normal torsion system. The "clean" sinus movement of the axle center point cannot be realized. As one of the axles has bearing on both of its hub seats, one degree of freedom is taken away, so the figure above is modified by both of the traction bogie, and the brake bogie. This makes a huge difference in the behavior and the movement of this special bogie on the track. The movements that are disappearing, can be seen on Fig. 4 .

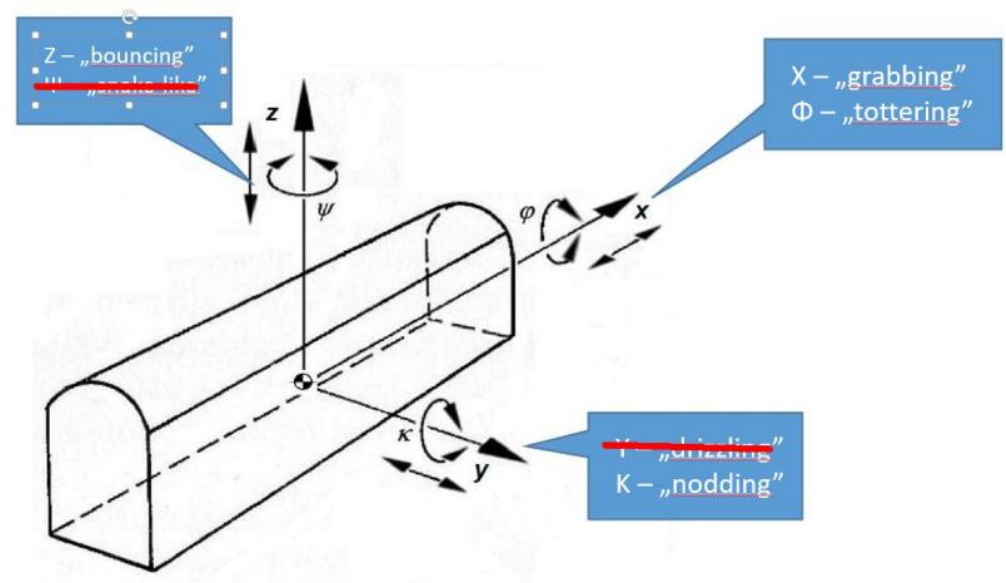

Figure 4: The altered irregular movements of a rack railroad car (Source: The authors own drawing)

As a conclusion, it can be stated, that by the traction axle, the angle speed of the two wheels, are not identical! So the wheels play only a support function on this specific axle, when it is not set to adhesive mode. The traction and braking forces are not attacking the rail via the wheel itself, as it happens by the classic rigid wheel joint.

\subsection{Derailment possibilities}

The attacking forces, that are affecting the normal railroad vehicle's running on the rail, are schematically demonstrated on Fig. 5.

Figure 5. - The force system attacking the wheel and the flange (The authors own drawing) 
The crossing point of the force attack lines, is where the flange touches the rail. The force that goes across the crossing point and has a 90 degree angle with the touching surface is marked with $F_{n}$, the $G$ means the gravity force, and $\mathrm{F}_{\mathrm{e}}$ is their equal as a resulting force that pushes the wheel flange towards the rail. On Fig.5. , we can see the profile of the rail on the point of derailment, and the real profile of the derailed wheel flange of the vehicle. This has been profiled using a laser profile scanner (CALIPRI C4X).

According to the Nadal-formula, until the wheel flange only touches one point on the rail surface, or it touches the rail surface within a limited extent, the derailment will not occur. But at the very moment, when the situation on Fig.6. becomes real, the flange will climb on the side of the rail, and the axle will derail.

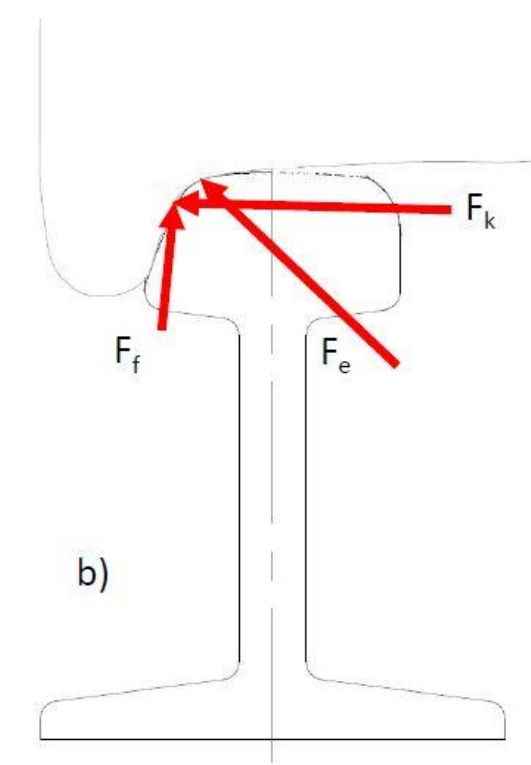

Fig.6. - The derailment force alignment according to Nadal

The profiles are the reality above. The attack point of $\mathrm{F}_{\mathrm{e}}$ went higher on the flange, while - as the forces went out from equilibrium, the $\mathrm{G}$ force transformed to a lift force (marked with $\mathrm{F}_{\mathrm{f}}$ ) and the forces have lost their one point of attack line crossing. The wheel flange profile, and the rail surface was identical, but this would not be enough for derailment alone. The scene assessment stated, that the outer rail in the curve had a blind underlay, so did not hold the wheel flange itself. Then, the underlay reached such a value, where the support rail surface was below the rack itself.

Normally, if we talk about a stiff axle, with fixed wheels, the angular speed of the two wheels would be identical, so the wheel would normally not leave the rail. But here the angular speeds are different, and the axle gets elevated from the rail, as the cogwheel takes the weight what the specific wheel must carry, and as the centripetal force pushes it, the teeth slip out of the rack, and the bogie derails. 


\section{Conclusion ${ }^{2}$}

After numerous measurements on the track itself, and laser-modeling it, taking numerous video recordings, we can state that the rack railway traction bogie or brake bogie is significantly more sensitive to the track's super elevation, and the geometry of the rack between the two rails. The assimetric bogie weight distribution also helps to the bogie to turn around the center place, and this movement is also helped by the cogwheel. The measurement is currently in progress to determine the marginal force, and the minimum elevation of the curve's outer rail, for to avoid such derailments. The marginal situation where the wheel derails, can be seen on Fig.7.

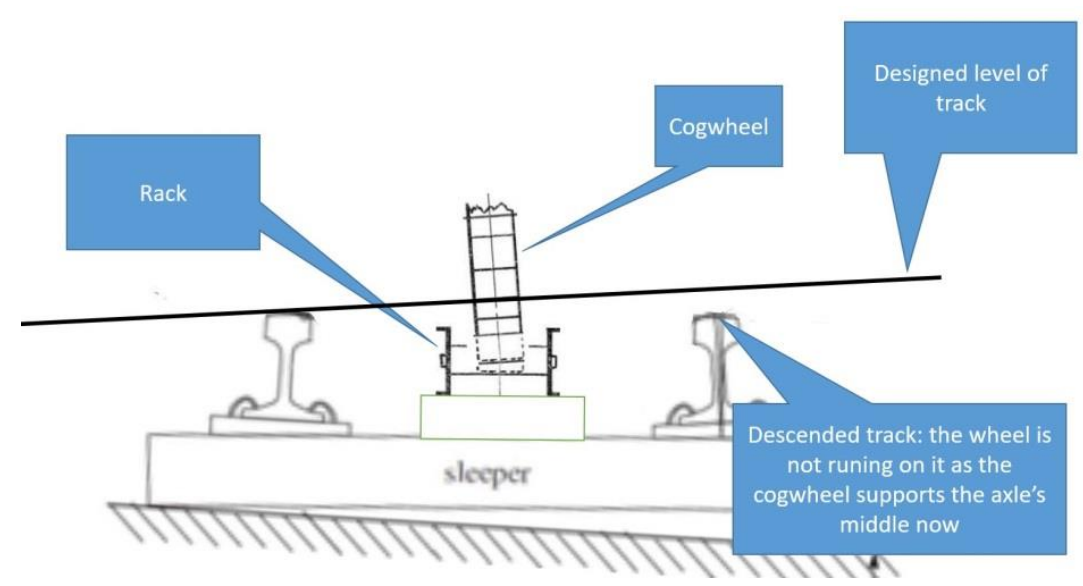

Fig.7. - The derailment situation where the cogwheel becomes the support (The authors own drawing)

\section{References}

[1] Web reference: https://en.wikipedia.org/wiki/Rack_railway, (2018.11.15)

[2] Andor NAGY - Prof.Dr. habil. István Lakatos Ph.D: Differences in the behavior of normal and rack railway vehicle's bogie on track: ISCAME 2018 Paper, Debrecen, 2018 